\section{REFERENCES}

1 Rosen SH, Castleman B, Liebow AA. Pulmonary alveolar proteinosis. N Engl J Med 1958; 258: 1123-1142.

2 Kitamura T, Tanaka N, Watanabe J, et al. Idiopathic pulmonary alveolar proteinosis as an autoimmune disease with neutralizing antibody against granulocyte/macrophage colony-stimulating factor. J Exp Med 1999; 190: 875-880.

3 Seymour JF, Presneill JJ. Pulmonary alveolar proteinosis: progress in the first 44 years. Am J Respir Crit Care Med 2002; 166: 215-235.

4 Sakagami T, Beck D, Uchida K, et al. Patient-derived granulocyte/ macrophage colony-stimulating factor autoantibodies reproduce pulmonary alveolar proteinosis in nonhuman primates. Am J Respir Crit Care Med 2010; 182: 49-61.

5 Seymour JF, Presneill JJ, Schoch OD, et al. Therapeutic efficacy of granulocyte-macrophage colony-stimulating factor in patients with idiopathic acquired alveolar proteinosis. Am J Respir Crit Care Med 2001; 163: 524-531.

6 Venkateshiah SB, Yan TD, Bonfield TL, et al. An open-label trial of granulocyte macrophage colony stimulating factor therapy for moderate symptomatic pulmonary alveolar proteinosis. Chest 2006; 130: 227-237.
7 Tazawa R, Hamano E, Arai T, et al. Granulocyte-macrophage colony-stimulating factor and lung immunity in pulmonary alveolar proteinosis. Am J Respir Crit Care Med 2005; 171: 11421149.

8 Bonfield TL, Kavuru MS, Thomassen MJ. Anti-GM-CSF titer predicts response to GM-CSF therapy in pulmonary alveolar proteinosis. Clin Immunol 2002; 105: 342-350.

9 Tazawa R, Trapnell BC, Inoue $\mathrm{Y}$, et al. Inhaled granulocyte/ macrophage-colony stimulating factor as therapy for pulmonary alveolar proteinosis. Am J Respir Crit Care Med 2010; 181: 13451354.

10 Uchida K, Nakata K, Suzuki T, et al. Granulocyte/macrophagecolony-stimulating factor autoantibodies and myeloid cell immune functions in healthy subjects. Blood 2009; 113: 2547-2556.

11 Bonfield TL, Raychaudhuri B, Malur A, et al. PU.1 regulation of human alveolar macrophage differentiation requires granulocytemacrophage colony-stimulating factor. Am J Physiol Lung Cell Mol Physiol 2003; 285: L1132-L1136.

\title{
Deficit of osteoprotegerin release by osteoblasts from a patient with cystic fibrosis
}

\section{To the Editors:}

Cystic fibrosis (CF) is an autosomal recessive disorder caused by mutations of the CF transmembrane conductance regulator (CFTR), a cyclic adenosine monophosphate (cAMP)-dependent anion channel expressed mostly in epithelia. Bone deficiency is commonly seen in patients with $\mathrm{CF}$ and begins at a young age. Low bone mass affects children and young adults with CF and is associated with significant morbidity due to fractures and decreased lung function. Brittle bones in CF disease have been confirmed by densitometric data, the presence of fractures, and impaired quality of life of young and adult patients [1]. Whether or not this is caused by bone disease around puberty due to a poor acquisition of peak bone mass and worsens with age, lower bone mineral density (BMD) gains are already being observed in $\mathrm{CF}$ children with mild disease and normal nutritional status, suggesting that CF-related low BMD may, in part, be due to a primary defect in bone metabolism [2]. In human bone cells, the expression of CFTR protein has been identified by immunohistological observations [3]; we further reported the expression of CFTR mRNA and protein in primary human osteoblasts (the cells of bone formation) [4]. Although there is a report demonstrating a direct association between the F508del mutation and CF-related low BMD in young CF adults with at least one F508del allele [5], the effect of mutations in CFTR, specifically the F508del allele in bone cell metabolism is, to date, unknown.

Since its initial discovery in 1997 as a key regulator in bone density [6], osteoprotegerin (OPG), a product of osteoblasts, is now well known as an inhibitor of osteoclastogenesis. The OPG protein has been shown not only to inhibit osteoclast-mediated bone resorption, but also to exert direct osteoanabolic effects by increasing alkaline phosphatase activity and mineralisation in human osteoblasts [7]. To our knowledge, it is not known whether the F508del mutation in CFTR has a direct effect on human osteoblast activity.

Here, we report, for the first time, both defective CFTR-mediated chloride channel activity and a severe deficit of OPG protein release by osteoblasts of a 25 -yr-old CF male with the F508del/ G542X mutation in CFTR. The CFTR-mediated chloride channel activity and the level of OPG release were investigated in primary osteoblasts cultured from fresh ankle bone fragments from the CF patient. Normal human osteoblasts, used as controls, were obtained from fresh bone fragments of healthy young adults who underwent trauma surgery. All CF and normal primary osteoblast cell culture (used at the second to third passage and after confluence within 6-8 weeks) was performed as previously described [4]. The bone samples were obtained with informed patient consent after approval by the local research ethics committee (Faculty of Medicine, Reims, France).

First, to test the chloride channel activities in primary human osteoblasts, functional analysis was performed by measuring the cAMP-regulated and CFTR-dependent iodide efflux in the presence of a mixture composed of forskolin (an adenylate cyclase activator raising the cellular cAMP level) and genistein (a direct activator of CFTR), as previously described [8]. As shown in figure $1 \mathrm{a}$, a total absence of CFTR-dependent chloride response in F508del-CFTR osteoblasts was observed compared with normal osteoblasts. Interestingly, the two calcium-dependent and volumedependent chloride channels were found to be fully functional in both F508del-CFTR and normal osteoblasts. Secondly, we demonstrated that the level of both basal and stimulated (tumour necrosis factor- $\alpha, 20 \mathrm{ng} \cdot \mathrm{mL}^{-1}$ for $4 \mathrm{~h}$ ) release of OPG protein (evaluated by ELISA) in F508del-CFTR osteoblast cultures was approximately $8-10 \%$ of that observed in normal osteoblasts (fig. 1b). 

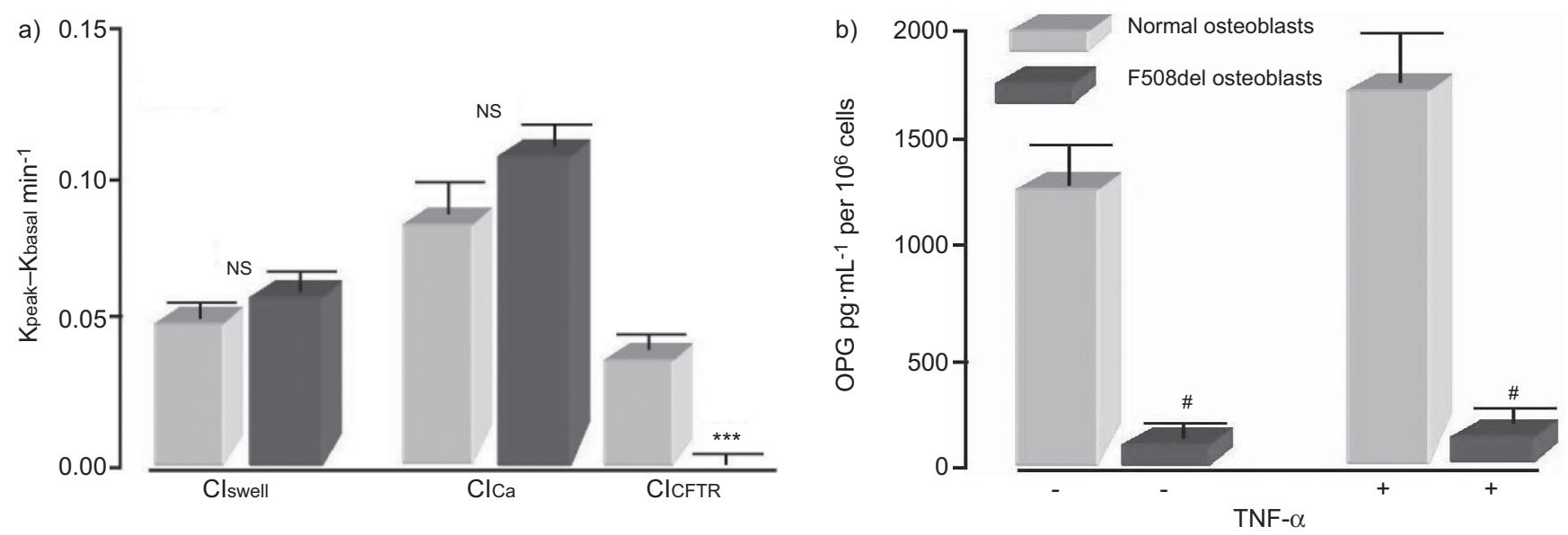

FIGURE 1. a) Chloride channel activities in F508del cystic fibrosis transmembrane conductance regulator (CFTR) and normal primary human osteoblasts. CFTRdependent $\left(\mathrm{Cl}_{\mathrm{CFTR}}\right)$, calcium-dependent $\left(\mathrm{Cl}_{\mathrm{Ca}}\right)$ and volume-dependent $\left(\mathrm{Cl}_{\text {swell }}\right)$ chloride channels were stimulated with a mixture of forskolin $(10 \mu \mathrm{M})$ and genistein $(30 \mu \mathrm{M})$, by the calcium ionophore A23187 ( $1 \mu \mathrm{M})$ and by a hypo-osmotic challenge, respectively. $\mathrm{n}=4$. b) Level of osteoprotegerin (OPG) protein release by cultured F508del-CFTR and normal primary human osteoblasts maintained for a 4-h period in the absence (-) and presence (+) of tumour necrosis factor $(\mathrm{TNF})-\alpha\left(20 \mathrm{ng} \cdot \mathrm{mL}^{-1}\right) . \mathrm{n}=3$. Data are presented as mean \pm SEM. NS: nonsignificant. ${ }^{*}: p<0.005$ compared with normal osteoblasts. ${ }^{* *}: p<0.001$ compared with normal osteoblasts.

The cause of the CF-related low BMD is multifactorial, including vitamin $\mathrm{K}$ and D insufficiency, calcium malabsorption, malnutrition, glucocorticoid use, delayed puberty, and pulmonary infection/systemic inflammation [1]. Whether CFTR activity plays a direct role in BMD is unknown, but this has been hypothesised on the basis of animal studies with the CFTR-null mouse. Smaller bones with decreased BMD were found in CFTR-/- mice, despite no difference in osteoblast and osteoclast numbers, suggesting that CFTR protein may influence bone cell activity rather than number [9].

In young adults with $\mathrm{CF}$, levels of serum OPG were found to be significantly lower when compared with those of normal controls [10]. Our discovery that there is both a defective CFTR-mediated chloride activity and a severe deficit of OPG release by F508del-CFTR osteoblasts increases the interest in the possible role of the CFTR gene in bone development and pathophysiological processes. The severe deficit of OPG secretion may explain, in part, the low BMD and enhanced bone resorptive activity reported in children and young adults with the F508del mutation $[2,5,10]$. If the key regulatory cascade for OPG production and release can be elucidated, it can open the door for a new therapy for CF-related bone disease by means of controlling OPG production.

\section{A. Gimenez-Maitre*, C. Le Henaff*, C. Norez C. Guillaume*, B. Ravoninjatovo", D. Laurent-Maquin*, F. Becq" ${ }^{\#}$ and J. Jacquot*}

*Inserm UMR-S 926, IFR 53, Faculté de Médecine, `Service des Maladies Respiratoires, CHU de Reims, Reims, and "Institut de Physiologie et Biologie Cellulaires, Université de Poitiers, CNRS, Poitiers, France.

Correspondence: J. Jacquot, Inserm UMR-S 926, Faculté de Médecine, IFR 53, 1 rue du Maréchal Juin, 51095 Reims, France. E-mail: jacky.jacquot@inserm.fr
Support Statement: This study was supported by research grants from the French Association Vaincre la Mucoviscidose and the Region Champagne Ardenne, France.

Statement of Interest: None declared.

\section{REFERENCES}

1 Haworth CS. Impact of cystic fibrosis on bone health. Curr Opin Pulm Med 2010; 16: 616-622.

2 Sermet-Gaudelus I, Castanet M, Retsch-Bogart G, et al. Update on cystic fibrosis-related bone disease: a special focus on children. Paediatr Respir Rev 2009; 10: 134-142.

3 Shead EF, Haworth CS, Condliffe AM, et al. Cystic fibrosis transmembrane conductance regulator (CFTR) is expressed in human bone. Thorax 2007; 62: 650-651.

4 Le Heron L, Guillaume C, Velard F, et al. Cystic fibrosis transmembrane conductance regulator (CFTR) regulates the production of osteoprotegerin (OPG) and prostaglandin (PG) $\mathrm{E}(2)$ in human bone. J Cyst Fibros 2010; 9: 69-72.

5 King SJ, Topliss DJ, Kotsimbos T, et al. Reduced bone density in cystic fibrosis: $\Delta \mathrm{F} 508$ mutation is an independent risk factor. Eur Respir J 2005; 25: 54-61.

6 Simonet WS, Lacey DL, Dunstan CR, et al. Osteoprotegerin: a novel secreted protein involved in the regulation of bone density. Cell 1997; 89: 309-319.

7 Grundt A, Grafe IA, Liegibel U, et al. Direct effects of osteoprotegerin on human bone cell metabolism. Biochem Biophys Res Commun 2009; 389: 550-555.

8 Norez C, Antigny F, Noel S, et al. A cystic fibrosis respiratory epithelial cell chronically treated by miglustat acquires a non-cystic fibrosis-like phenotype. Am J Respir Cell Mol Biol 2009; 41: 217-225.

9 Haston CK, Li W, Li A, et al. Persistent osteopenia in adult cystic fibrosis transmembrane conductance regulator-deficient mice. Am J Respir Crit Care Med 2008; 177: 309-315.

10 Shead EF, Haworth CS, Barker H, et al. Osteoclast function, bone turnover and inflammatory cytokines during infective exacerbations of cystic fibrosis. J Cyst Fibros 2010; 9: 93-98.

DOI: $10.1183 / 09031936.00104111$ 